\title{
EDITORIAL
}

\section{AI EDAM at 20}

DAVID C. BROWN

Computer Science Department, Worcester Polytechnic Institute, Worcester, Massachusetts, USA

The AI EDAM journal published its first issue in 1987. Now, amazingly, 20 years later, this issue starts the journal's third decade.

Let me start with thanks. Clive Dym was the Founding Editor, and he remains supportive and attentive. Bill Birmingham, who took over from Clive, continued to develop and modernize the journal. To both I owe a huge debt of gratitude for shaping the journal's character and putting it on the map.

Behind the scenes there has been some tremendous support. The Cambridge University Press journal department's staff in New York, especially Morrell Gillette, Production Editor, have been very supportive. In recent years, David Tranah, Publishing Director for Mathematical Science and Information Technology, has been very encouraging. Last, and certainly not least, I thank Nancy BriggsShearer, Project Managing Editor, who manages the task of getting every issue into print. It is a difficult and detailed job, and she does it extremely well.

Over the years, AI research has been changing. In order to reflect that, there have been matching changes to the scope of the journal. Although the published scope has not changed very much, there has been an increasing amount of editorial latitude given to what constitutes an acceptable topic-all the while attempting to maintain high standards of originality and quality.

I now tend to be quite liberal about what does and does not count as AI. My usual test if there is not an explicit sign of an established AI technique in the article is to see whether some intelligent behavior is being modeled or explained, or, more often, whether there is some knowledge represented. This takes us from functional reasoning on the one hand to linguistic knowledge on the other hand, for example. I also have to make decisions about whether an article's domain is "engineering" or not.

Reprint requests to: David C. Brown, Computer Science Department, Worcester Polytechnic Institute, 100 Institute Road, Worcester, MA 01609, USA. E-mail: aiedam@cs.wpi.edu
Quality can only be maintained by attracting high quality papers in the first place, and by finding the best reviewers possible. In addition, I have worked hard to increase the amount of feedback provided to the authors so that revised papers are of higher quality. In addition to carefully selected expert reviewers, every paper is reviewed by an Editorial Board member, bringing experience, high standards, and a lot of background knowledge to bear. Our acceptance rate is currently at about $30-40 \%$.

As Editor in Chief, my personal opinions about the field (and about individual papers) are usually kept fairly well in check: reviewers get to decide what is good and what is not. However, I am concerned about the increasing number of "neuro-fuzzy-evolutionary" papers being submitted.

First, I am concerned because many are just applying powerful but general techniques to a problem, which is often a small problem, with the only result being that they could actually do it. Our standards mandate the inclusion of a comparative evaluation with other techniques and solutions for the problem, and a discussion of what makes the problem hard and why the chosen technique is appropriate. A strong evaluation is important.

Second, I am concerned because I personally do not find neuro-fuzzy-evolutionary techniques very interesting. Although they can be used to solve problems, it is rare that their use reveals insights into the problem: they are not really linked to types of reasoning or types of knowledge.

I have a sense that $\mathrm{AI}$ is once again moving back into a more mechanical tool/techniques bias with a focus on formality. It reminds me of when AI researchers expended great effort on figuring out new ways to handle conflict sets of rules. It also reminds me of Bobrow's famous question, "If Prolog is the answer, what is the question?" (1984). Our journal's questions ought to be about the nature of reasoning and knowledge in Engineering Design, in Analysis, and in Manufacturing.

One way we are trying to focus the journal on such questions is by having a rich variety of Special Issues. We would like to have the journal associated with cutting edge research. The hope is that Special Issues about exciting new areas 
will inspire additional research, and that these Special Issues will become a key resource. Please investigate upcoming Special Issues at the Editor's Web pages (www.cs.wpi.edu/ $\sim$ aiedam/) and get involved.

It is always tough to predict the future and decide which new topics will become important-I have to rely on workshop organizers and other researchers to point the way. Unfortunately, there is always a chance that the issues will miss the mark. In addition, the focused nature of those Special Issues leads to fewer citations in the short term until others catch up with the cutting edge. However, as various Special Issues on Configuration point out, being there at the beginning is a good thing.

Out of curiosity I found the top 10 cited AI EDAM papers according to Google Scholar (scholar.google.com). It is noteworthy that several are from Special Issues. Here is the list, from most cited (114) to least (35):

1. Supporting conceptual design based on the functionbehavior-state modeler, by Y. Umeda et al., 1996

2. Function-behavior-structure paths and their role in analogy-based design, by L. Qian and J.S. Gero, 1996

3. A computational market model for distributed configuration design, by M.P. Wellman, 1995

4. Toward a general ontology of configuration, by $\mathrm{T}$. Soininen, J. Tiihonen, T. Mannistro, and R. Sulonen, 2000

5. A classification and constraint-based framework for configuration, by D. Mailharro, 2000

6. Integrating different perspective on design rationale: Supporting the emergence of design rationale, by F.M. Shipman and R.J. McCall, 1997

7. Conceptual modeling for configuration: A description logic-based approach, by D.L. McGuinness and J.R. Wright, 2000

8. Product platform design and customization: Status and promise, by T.W. Simpson, 2005

9. Functional descriptions used in computer support for qualitative scheme generation "Schemebuilder," by R.H. Bracewell and J.E.E. Sharpe, 1996
10. On research methodology towards a scientific theory of engineering design, by J.R. Dixon, 1987

Apart from Jack Dixon's seminal paper, the rest are within the last 10 years, and almost half of them from the past 5 years, mostly due to a great Special Issue on Configuration.

The rest of this Anniversary Year Volume is devoted to three very interesting Special Issues. Issue 2 is about Computational Linguistics for Design, Maintenance and Manufacturing, edited by Nicole Segers and Pierre Leclercq. Issue 3 concerns Support for Design Teams, edited by Renate Fruchter and Mary Lou Maher. Lastly, issue 4 provides a sample of the best work from the Second International Design Computing \& Cognition (DCC'06) Conference, edited by Andy Dong and John Gero.

This first issue of the year starts by celebrating the 20th Anniversary with editorial comments from members of the AI EDAM Editorial Board. Some comments were solicited and some volunteered. We start with both of the previous Editors in Chief, move to the two Associate Editors, and end with the Board members. I think you will enjoy their variety and their challenges.

The remainder of the issue has four widely differing papers that reflect the exciting richness of the journal's submissions. Ivey Chiu and Lily Shu's paper is concerned with natural language, acting as an excellent lead-in to the upcoming Computational Linguistics Special Issue. The paper by Chiara Catalano, Franca Giannini, Marina Monti, and Giuliana Ucelli is related to the recent Special Issue on Style. Byungwoo Lee and Kazuhiro Saitou address a more manufacturing-oriented topic. The remaining paper, by Jeremy Butkovich and Youssef Hashash, describes an approach to modeling soil behavior.

I hope that you will enjoy this 20th anniversary year of AI EDAM, and that you will still be enjoying it at the 30th!

\section{REFERENCE}

Bobrow, D.G. (1984). If Prolog is the answer, what is the question? Proc. Int. Conf. Fifth Generation Computer Systems, pp. 138-145. 